- accepted for publication in Glottotheory -

\title{
Language change and language evolution: Cousins, siblings, twins?
}

Stefan Hartmann, University of Düsseldorf

\begin{abstract}
The relationship between "language change" and "language evolution" has recently become subject to some debate regarding the scope of both concepts. It has been claimed that while the latter used to refer to language origins in the first place, both terms can now, to a certain extent, be used synonymously. In this paper, I argue that this can partly be explained by parallel developments both in historical linguistics and in the field of language evolution research that have led to a considerable amount of convergence between both fields. Both have adopted usagebased approaches and data-driven methods, which entails similar research questions and similar perspectives on the phenomena under investigation. This has ramifications for current models and theories of language change (or evolution). Two approaches in particular - the concept of complex adaptive systems and construction grammar - have been combined in integrated approaches that seek to explain both language emergence and language change over historical time. I discuss the potential and limitations of this integrated approach, and I argue that there is still some unexplored potential for cross-fertilization.
\end{abstract}

Keywords: evolutionary linguistics, biolinguistics, historical linguistics, history of linguistics

\section{Introduction}

There have been many attempts to investigate language change in the light of evolutionary theory. Recent examples include Haspelmath's (1999a) concept of "diachronic adaptation", which is inspired by evolutionary biology, Croft's (2001) evolutionary model of language change, and Ritt's (2004) Darwinian approach to sound change. This is not an entirely new idea, of course - Darwin himself noted "curious parallels" between language change and biological evolution (see Atkinson and Gray 2005), and especially the late $19^{\text {th }}$ century has seen a significant amount of cross-fertilization between the work of linguists and biologists such as Schleicher and Darwin (see e.g. Greenberg 2005; Frank 2008; Frank and Gontier 2010). Throughout most of the $20^{\text {th }}$ century, explicitly evolutionary accounts of language change have been rare, but as the examples above show, the decades since 1990 have seen a surge in theories that explicitly link up language change with evolutionary theory.

Roughly at the same time, research on the origins of language became increasingly widespread. The publication of Bickerton (1990) and Pinker and Bloom (1990) is often considered the start- 
ing point of the field that is usually called language evolution research or "evolutionary linguistics" (see e.g. Fitch 2010: 16; regarding the terminology, see Section 2). As e.g. Dediu and De Boer (2016) and Fitch (2017) point out, the increased availability of empirical data and methods has been a main factor in elevating the study of language evolution from a speculative enterprise to a serious science. Insights from cross-species comparative studies, experimental approaches, and computational modeling can now be combined to inform hypotheses about how language could have emerged from "proto-linguistic" communication systems (see e.g. Fitch 2010). In a blog post discussing Dediu and De Boer's (2016) editorial to the first issue of the Journal of Language Evolution, Haspelmath (2016) argues that the distinction between the terms "language change" and "language evolution" has blurred over the past 20 years or so (also see Haspelmath 2020). While it used to refer almost exclusively to the emergence of language as a human-specific trait, it came to be used for "language change studied from the perspective of variation and selection" as well. Ultimately, it was also used to refer to language change in general - or more precisely "language change at a global (or large-scale) level" - even if it was not studied from an explicitly evolutionary perspective.

If Haspelmath's observations are correct, then we are dealing with a purely terminological issue: Historical linguists have started to use the term "language evolution" referring to "language change" - potentially because it seemed more fashionable (or "sexy", as Haspelmath puts it). In this paper, however, I will argue that the terminological change observed by Haspelmath is symptomatic of a much more far-reaching development. More specifically, I will argue that both fields - historical linguistics and language evolution research - have started to converge on very similar research questions and, perhaps most importantly, a shared methodological toolkit.

These developments, which I discuss in more detail in Section 2, go in tandem with the emergence of integrated theories of the incipient development and continued evolution of language. As I will argue in Section 3, the broadening of perspectives in recent research goes even further in that many researchers have started to view language in its broader context, considering language evolution as one kind of cultural evolution. I will show that numerous recent publications have suggested a constructionist complex adaptive systems approach as an overarching framework for studying the development of language across different timescales (biological, ontogenetic, historical) and in its sociocultural context. I argue that the combination of the network metaphor that lies at the heart of usage-based construction grammar with a complex adaptive systems approach yields a simple but powerful model that is inherently dynamic. The "catchall" nature of the model is both its strength and its weakness, though - one could argue that the model is too general in that it is not always clear which predictions can be derived from it. However, it provides a good framework for the data-driven investigation of language dynamics, which in turn can help flesh out the theoretical "skeleton" that the integrated model offers. 


\section{From skepticism to convergence: A brief history of the relationship between historical linguistics and language evolution research}

When the field of language evolution research was in its nascence, historical linguistics could already look back at a fairly long history - or so it seems; in fact, matters are of course much more complex. But there appears to be a broad consensus that the work of people like Humboldt, Jacob and Wilhelm Grimm, Schleicher, and the Neogrammarians in the $19^{\text {th }}$ century constitute the starting point of historical linguistics proper (e.g. Collinge 1995; Crowley and Bowern 2010; Bowern and Evans 2014, among many others), while language evolution research - or "evolutionary linguistics", as it is sometimes called (e.g. Kirby 2017, but see below) - established itself as a field from the 1990s onwards. Apart from Pinker and Bloom's (1990) seminal paper and Bickerton's (1990) monograph, the first Evolang conference in 1996 is often seen as a landmark in the consolidation of language evolution research as a discipline (Dediu and De Boer 2016: 2; Trotzke 2017: 4). This does not mean, however, that there has been no research on the origin of language earlier in the $20^{\text {th }}$ century - by way of example, Fitch (2010: 16) mentions Hockett and Ascher (1964), Hewes (1973), and Harnad et al. (eds.) (1974). The list could easily be extended (see Dediu and De Boer 2016: 1 for further examples), and considerations about the evolution of language can of course be found in many of the early seminal works of historical linguistics such as Adelung (1781), Humboldt (1836), and Schleicher (1863). Also, returning to the late $20^{\text {th }}$ century for now, more than a decade before the Evolang series of conferences began with the 1996 edition in Edinburgh, the Language Origins Society had started organizing a biennial conference (see Dediu and De Boer 2016: 2). However, according to Foster (2000: 226), those conferences did not have the scientific standards that Evolang came to establish ("there's no screening, anybody can come to give a paper"). ${ }^{1}$ As such, it seems fair to say that despite some more or less stray attempts of investigating the emergence of language, it was only the 1990s that saw a consolidation and solidification of language evolution research as a scientific discipline.

Historical linguistics, on the other hand, had arguably undergone diversification throughout the $20^{\text {th }}$ century. In his metascientific study of the history of historical linguistics, Maitz (2012) distinguishes three stages in the development of the discipline: A "progressive" phase in the late $19^{\text {th }}$ and early $20^{\text {th }}$ century is followed by a "stagnative" phase in which research questions and methods remain anchored in the Neogrammarian tradition. The 1970s, however, mark the beginning of a new era in which historical linguistics becomes "progressive" again. Maitz (2012: 6) mentions two key factors that led to this change, which he characterizes as a paradigm shift in the sense of Kuhn (1970): On the one hand, the dynamic aspects of language now also got recognized in other linguistic sub-disciplines; on the other hand, more and more historical

\footnotetext{
${ }^{1}$ This is not to say that the Evolang conferences so far have been devoid of the notorious speculative "just-so stories" which not only critics of language evolution research see as characteristic of the field - in fact, Fitch (2010: 16, 2017:4) laments the low scientific standard in the field, citing Jackendoff's (2002: 237) revealing remark, "I see no need at the moment to hold myself to a higher standard than the rest of the field."
} 
linguists started to question the Neogrammarian framework. Among other things, this led to the development of new sub-disciplines such as historical pragmatics and historical sociolinguistics (Maitz 2012: 7). One consequence of this diversification is that the scope of historical linguistics is conceptualized differently in different research traditions. The relevant English-language textbooks on historical linguistics such as Crowley and Bowern (2010), Campbell (2013), or Trask (2015) are largely rooted in the comparative-typological tradition of the field, emphasizing topics like sound change and the comparative method. However, at least since the advent of grammaticalization research (e.g. Heine et al. 1991; Heine and Kuteva 2002, Heine and Kuteva 2007; Hopper and Traugott 2003; Narrog and Heine [eds.] 2011; Lehmann 2015), the term "historical linguistics" is also used to refer to studies that focus more on the emergence (and continued evolution) of morphology and syntax than on sound change and that ask different research questions. While "classical" historical linguistics is certainly also interested in the explanation of language change (and in particular sound change), its focus has been on describing change and on deriving generalizations from the observed changes, ideally in the form of exceptionless laws - following Osthoff and Brugmann's (1878) postulate that "sound change suffers no exceptions", cited multiple times as the cornerstone of the comparative method in Campbell (2013). More functionalist-oriented historical linguistics, by contrast - which includes most grammaticalization research -, focused on identifying principles (Labov 1994, Labov 2001, and Labov 2010) of language change as well as their cognitive underpinnings and cultural motivations. Importantly, grammaticalization research essentially synthesizes different research strands such as typology, historical sociolinguistics, and culturally-oriented approaches to the study of language change, but also largely synchronically-oriented paradigms like cognitive linguistics (see e.g. Bybee 2007). Grammaticalization research therefore plays an important role in bridging the gap between synchrony and diachrony, which Maitz (2012), as mentioned above, sees as one important factor in the paradigm shift that historical linguistics has undergone since the 1970s.

This "panchronic" approach, then, is in many ways compatible with the gradualist view of language emergence that lies at the heart of much research into the emergence of language. Nölle (2014), following Steels (2011), points out that contemporary language evolution research can be divided into two predominant approaches: biolinguistics on the one hand, which "favors biological evolution, presupposes innate language capabilities and thus views language as a discontinuously evolved capacity", and evolutionary linguistics on the other, which

stresses cultural evolution and employs research traditions from cognitive linguistics, historical and comparative typology and anthropology to explore the underlying mechanisms and consequences of this evolution in a synchronic and diachronic manner. 
What is striking about this quote is that it could just as well refer to research on grammaticalization, which clearly shows a certain amount of convergence between (parts of) historical linguistics on the one hand and (parts of) language evolution research on the other. ${ }^{2}$

The division between "biolinguistics" and "evolutionary linguistics" of course echoes the gap between generative and usage-based/cognitive/functionalist approaches ${ }^{3}$ in general linguistics (see e.g. Harris 1993 on the history of this divide and Gong 2011 as well as Pleyer \& Hartmann 2019 for discussions on how the debate can potentially be resolved). Recent years have seen a short-lived resurgence of the "linguistics wars" in the wake of Evans' (2014) almost viciously polemic rebuttal of generative theory that led to a back and forth of reply articles (Adger 2015a; Behme and Evans 2015; Adger 2015b; for a more nuanced perspective, despite the slightly sardonic title, see Dąbrowska 2015). In historical linguistics, the generative-functionalist divide mainly pertains to assumptions regarding the loci of change (language acquisition vs. language use; see Hartmann 2018: 24-29). However, one may well argue that the divide was much less noticeable within the field of historical linguistics - what was noticeable instead were the repercussions of the success of generative linguistics in a different sense: Given the synchronic focus of generative linguistics, diachrony was relegated to a secondary position (see e.g. Murray 2006: 2479). Similarly, Fischer (2007: 250) notes that already since Saussure, historical linguistics had become subservient to synchronic linguistic theory. Maitz (2012) assumes that the above-mentioned paradigm shift in historical linguistics is partly a reaction to its diminishing relevance given the rise of "ahistorical" approaches (which of course also includes structuralism).

However, recent years have seen more and more attempts at bridging the gap between generativist and usage-based approaches. A multitude of studies has set out to reconcile explanations from both "camps" (see e.g. Adli 2004 on grammatical variation, Kempson and Cann 2007 on syntactic change, Korostenskienė 2017 on morphology, and Guzmán Naranjo 2019 on analogy, among many others). Also, at least two scholars have set themselves the task of "unifying everyhing" (Müller 2013; Guzmán Naranjo 2015). While linguistics as a whole is certainly far from such a unification, it might not be too bold to speak of a peaceful coexistence. Most scholars from both "camps" have come to appreciate that generative and usage-based accounts approach language from quite different perspectives, pursuing different research questions but ultimately describing the same observations with different scientific metaphors. What is more, there is an increasing awareness that dichotomies like "nature vs. nurture" or "modular vs. holistic" are too simplistic. For instance, not even the fiercest proponent of cognitive linguistics would deny that at least the cognitive prerequisites of language have a biological basis (see e.g. Dąbrowska 2015). In addition, there is increasing convergence between generative and usage-

\footnotetext{
${ }^{2}$ In the remainder of this paper, I will adopt Nölle's terminology and use "language evolution research" as a cover term for both "biolinguistic" and culturally-oriented approaches to language evolution.

${ }^{3}$ Needless to say, this twofold divide is a convenient simplification. There are of course numerous frameworks that sit "in-between" these approaches, and many different approaches can be differentiated under the labels of "generative linguistics" on the one hand and "usage-based linguistics" on the other.
} 
based linguistics regarding methodology. Even though generative linguistics has a reputation of being "armchair linguistics" (see e.g. Meyer 2002: 4), generatively-oriented linguists have increasingly adopted empirical methods such as quantitative corpus linguistics (e.g. Walkden 2013; Zimmermann 2017 - again, among many others).

As such, the empirical turn that characterizes contemporary linguistics as a whole may be a major unifying factor that drives the increasing convergence between generative and usagebased approaches. Interestingly, the situation is quite similar in the area of language evolution research. For a while, "biolinguistics" essentially referred to the saltationist account proposed by Chomsky, according to which "a rewiring of the brain took place in some individual, call him Prometheus, yielding the operation of unbounded Merge" (Chomsky 2010: 59; see e.g. Hauser et al. 2002 for further discussion). However, this arguably too simplistic account has attracted skepticism and criticism not only outside of but also within generative linguistics (see e.g. Benítez-Burraco and Longa 2010), and importantly, biolinguistic approaches have also started to put more emphasis on empirical evidence - in recent years, especially from the domain of genetics (see e.g. Theofanopoulou et al. 2017; Martins et al. 2018). As such, biolinguistics and evolutionary linguistics have come to study complementary aspects of language evolution. Given the broad consensus that cultural and biological factors conspire in the evolution of language (e.g. Kirby 2017, Smith 2018), the two research strands contribute, metaphorically speaking, different parts to the jigsaw puzzle of language evolution. And given that genetic findings are increasingly linked up with (historical or synchronic) language data (see e.g. Gray et al. 2011; Creanza et al. 2015; Dediu 2015), the biolinguistic approach also offers numerous points of convergence between language evolution research and historical linguistics. As we have seen above, early historical-comparative linguistics in the $19^{\text {th }}$ century was characterized by a significant interest in and cross-fertilization with biology. However, as Johansson (2005: 32) points out, the contact between historical linguists and biologists was short-lived, and for much of the $20^{\text {th }}$ century, linguists shunned biological metaphors. Also, contemporary historical linguistics mainly investigates the dynamics of language as a cultural trait. If at all, the biological foundations of language only play a marginal role in historical linguistics. As such, there are naturally more points of commonality between historical linguistics and evolutionary linguistics in the definition cited above than between historical linguistics and biolinguistics.

Despite these points of convergence, "traditional" historical linguists reacted to the emergence of language evolution research with some skepticism. For example, Campbell (2013: 2) clearly distinguishes historical linguistics from language evolution research ${ }^{4}$ :

Another topic not generally considered to be properly part of historical linguistics is the ultimate origin of human language and how it may have evolved from non-human primate call systems, gestures, or whatever, to have the properties we now associate with human languages in general.

\footnotetext{
${ }^{4}$ This passage has remained unchanged from the first edition of the book (Campbell 1999).
} 
Many hypotheses abound, but it is very difficult to gain solid footing in this area. Historical linguistic theory and methods are very relevant for research here, and can provide checks and balances in this field where speculation often far exceeds substantive findings, but this is not a primary concern of historical linguistics itself.

Joseph and Janda (2003: 116) go further in stating that "it is not obvious how the standard methodologies of historical linguistics can currently offer anything to illuminate this issue [viz. the origins of language, S.H.]". By contrast, scholars like Bybee $(2010,2012)$ or Heine and Kuteva (2012) argue that the same mechanisms that are at work in the evolution of language on a historical timescale can be assumed to drive the ultimate emergence of language. Evidence for this view comes from multiple sources, including experimental approaches in which participants have to ground novel communication systems (see e.g. Kirby 2017; Tamariz 2014, Tamariz 2017; Tamariz \& Kirby 2017 for reviews) and from emerging sign languages such as Nicaraguan Sign Language or Al-Sayyid Bedouin Sign Language (see e.g. Senghas 2005). It has therefore been argued that - contrary to Joseph and Janda's view - insights from historical linguistics can make major contributions to our understanding of language origins (see e.g. Bybee 2012; Heine and Kuteva 2012).

But this is only one aspect of the convergence between the fields. Just as in the case of the increasing convergence between biolinguistics and evolutionary linguistics, methodological developments can also be seen as a major driving force. The availability of large amounts of (historical) language data and the availability of an increasing amount of computational power have made it possible to apply quantitative methods in a way that would not have been possible just a few decades ago. Both in historical linguistics and in language evolution research, there is a general trend towards the application of ever more sophisticated statistical methods to increasingly large datasets. This makes massive cross-linguistic comparisons possible, which in turn can contribute to empirically testing theories of language dynamics (e.g. Lupyan and Dale 2010; Bentz 2018) as well as contribute new insights to linguistic reconstruction (e.g. Bouckaert et al. 2012). In the terminology of Roberts and Winters (2012), it makes a "nomothetic" rather than "idiographic" approach possible when it comes to studying the relationship between language (change) and sociocultural factors. While the idiographic approach consists of a careful study of individuals in a particular society, the nomothetic approach takes data across many languages and sources into account. Mutatis mutandis, this distinction - which is of course more a continuum than a dichotomy - also applies to other domains such as corpus linguistics (careful manual annotation vs. large amounts of manually tagged data) or typology (meticulous application of the comparative method on a case-by-case basis vs. large-scale automated cross-linguistic analysis).

Importantly, the topics and goals that lie at the very heart of "traditional" historical linguistics, viz. sound change and linguistic reconstruction, have been addressed using advanced statistical methods fairly early on in the "empirical revolution" that linguistics, like many other sciences, is currently witnessing. This may partly explain the rather dismissive reactions from traditional 
historical linguists against large-scale quantitative methods such as the phylogenetic approach used by Gray \& Atkinson (2003) for the reconstruction of language relationships (e.g. Campbell 2013; Pereltsvaig and Lewis 2015).

Language evolution research, on the other hand, is known to have an ambivalent relationship with historical linguistics: Gong et al. (2014: 508), discussing the $10^{\text {th }}$ Evolang conference in Vienna, criticize that historical linguistics "has been blocked by Evolang ever since 1996." However, they also acknowledge that the Vienna Evolang conference has embraced historical linguistics with no less than two workshops dedicated to "Evolutionary linguistics and historical language studies" (organized by Melanie Malzahn and Nikolaus Ritt) and "How grammaticalization processes create grammar: From historical corpus data to agent-based models" (organized by Luc Steels, Freek Van de Velde, and Remi van Trijp). This tendency continued at the $11^{\text {th }}$ Evolang in New Orleans, where Joan Bybee was one of the plenary speakers (see BarcelóCoblijn et al. 2016).

Very roughly, works explicitly combining historical linguistics and language evolution research can be divided into two groups: on the one hand, historical-linguistic studies that draw inspiration from evolutionary biology in their theoretical modeling of language change, such as those mentioned at the very beginning of this paper, and works that apply methods from fields such as evolutionary biology to historical-linguistic data (e.g. van Trijp 2014), potentially also discussing implications for language origins.

Summing up, we can say that (some branches of) historical linguistics have developed a significant degree of convergence with (some branches of) language evolution research. In both areas, those parts of the respective fields that are interested in explanative accounts of language dynamics, studying language in its sociocultural context, have actively sought cross-fertilization between the two fields. This development has arguably been boosted by the "empirical turn", which has also helped bridge the gap between generative and usage-based approaches in both fields.

\section{Language evolution and change: Towards an evolutionary synthesis}

The preceding discussion has shown that there has been considerable convergence between the fields of language evolution research and historical linguistics in the last 20 years. This leads us to the question of where exactly the two approaches meet regarding models and theories of language dynamics and change - and where they diverge.

In order to better appreciate the theoretical commonalities and differences, it may be helpful to return to the terminological difference discussed by Haspelmath (2016) and hinted at in the title of this paper: To what extent do the terms "language change" and "language evolution" refer to the same phenomena?

Interestingly, one of the "outstanding questions" raised in Hruschka et al. (2009: 468) is: "Are the processes involved in language change and language evolution of the same or different kinds?" - Mufwene (2001) uses both terms, but he only discusses the term "language evolution" 
in detail: "By evolution, I mean no more than the long-term changes undergone by a language (variety) over a period of time." (Mufwene 2001: 12, emphasis added) Johansson (2005: 2) treats "language change" as a hyponym of "language evolution": "The diachronic processes of language change is a form of language evolution" (emphasis added). This is in line with Rosenbach's (2008) division of language evolution into biological and cultural evolution. On this view, language change refers to the cultural evolution of language. Christiansen and Chater (2008: 504) are a bit more ambiguous in their use of the terms: In a section entitled "Language evolution as linguistic change", they suggest that "observable historical change may be continuous with language evolution" (which implies that "language evolution" only refers to the emergence of language here).

These selective examples already show a certain tendency, which can be spelled out in more detail in the following definitions: Language evolution refers to (i) the emergence of the biological capacity for language as well as to (ii) the cultural evolution of language from prelinguistic (and/or proto-linguistic ${ }^{5}$ ) communication systems, and (iii) the continued cultural evolution of fully-fledged language(s) over historical time. Regarding the last aspect, the definition of language evolution intersects with the definition of language change. However, the intersect is only partial, as the term "language change" arguably covers phenomena not covered by "language evolution". Language change refers to change of linguistic features at all levels of abstraction as well as to changes in the pragmatic conventions of when and how a specific linguistic unit is used. As Haspelmath (2016) correctly observes, language evolution in the broad(ened) sense refers to "language change at the global level". As such, it would seem odd to apply the term language evolution to individual instances of language change. Even when dealing with a fairly far-reaching development such as the gradual development of a new grammatical category - say, a perfect or a future construction -, one would not necessarily speak of "language evolution", even though one might speak of the evolution of a category and potentially also choose metaphors from evolutionary biology like variation and selection to describe the development. ${ }^{6}$ One might therefore argue that the study of language evolution is always concerned with the bigger picture: Its primary goal is to arrive at a better understanding of the mechanisms that are at play in the evolution of language, assuming that, at least regarding the cultural evolution of language, these mechanisms essentially are the same in present-day languages as in the earliest stages of human language.

This latter assumption, however, might be problematic to a certain degree because it does not take biological evolution into account and as such relies on a fairly strong version of the uniformitarian hypothesis. Given the idea of a co-evolution between language and the brain (Deacon 1997; Christiansen and Chater 2008), the assumption that the human cognitive makeup has not changed at all since the origin of language has been called into question. Levinson (2012)

\footnotetext{
${ }^{5}$ On the notion of protolanguage, see e.g. Tallerman (2012) and Pleyer (2017).

${ }^{6}$ The same applies for the use of the term evolution when speaking about the development of individual linguistic units, e.g. "[t]he evolution of the genitive case marker of Old English into the modern English possessive morpheme" (Taylor 1996: 128), where evolution is used in a non-technical sense.
} 
goes even further, arguing uniformitarianism to be "the original sin of cognitive science". 7 Drawing on findings from multiple disciplines, he argues that there is much more cognitive variation and diversity than is traditionally acknowledged in the cognitive sciences. As such, to the extent that historical linguistics aims to account for the cognitive underpinnings of language change, it can benefit from taking biological considerations into account as well. As Malzahn and Ritt (2014) have put it in the description of their above-mentioned Evolang workshop on evolutionary linguistics and historical language studies,

the study of historical language development depends on a solid understanding of the biologically evolved underpinnings of the human language faculty, as they naturally constrain the design space within which the histories of specific languages may unfold, and/or may specify pathways of likely developments. ${ }^{8}$

The interaction between biology and culture is, however, an inherent part of the framework that keeps enjoying growing popularity as a major link between not only historical linguistics and language evolution research, but also many other disciplines. In this framework, language is conceptualized as a complex adaptive system, i.e. a system with multiple agents that is adaptive in that the agents continually adjust their behavior based on their past interactions and thus give rise to some sort of structure, e.g. linguistic structure (see e.g. Beckner et al. 2009; Kirby 2012; Massip-Bonet 2013). This view bears some similarity to Keller's (1994) invisible-hand theory, according to which language change can be understood as the unintended result of a multitude of independent intentional actions of many individuals. The structures that emerge in this way, even though they are unplanned, give the appearance of "design without a designer" (Cornish 2010). Unlike Keller's theory of language change, the complex adaptive systems framework is not limited to language - classic examples of complex adaptive systems include ant colonies and the human brain (Schoenemann 2017: 67-68). Importantly, this approach offers a unified framework for the evolution of very different biological and cultural traits. This is in line with an important focus shift that goes in tandem with the developments sketched in Section 2: Language has increasingly come to be viewed in the context of other cultural and communicative systems. While the special status of human language is undisputed, it is interesting to see that other domains exhibit dynamics that are very similar to those that can be observed in the diachronic development of language. Consider, for instance, the evolution of writing systems, which often show a drift from iconicity to symbolic representation (Garrod et al. 2007) - a path that can also be seen, for example, in the development of homesign systems (Goldin-Meadow 2007; Coppola and Brentari 2014) or in emerging sign languages (Senghas 2000). Interestingly, the study of cultural evolution (e.g. Boyd and Richerson 1985, Boyd and Richerson 1996; Richerson and Boyd 2005) has arguably also developed into a discipline in its own

\footnotetext{
${ }^{7}$ But see e.g. Arbib (2016) on different construals of uniformitarianism.

${ }^{8} \mathrm{https}$ ://evolangx.univie.ac.at/fileadmin/user_upload/p_evolangx/ws_proposal_histling_evoling_2.pdf (last accessed 31/10/2018)
} 
right: In 2017, the Cultural Evolution Society was officially founded at its inaugural conference in Jena. Language evolution research is of course also part of this enterprise, but the perspective is much broader and includes, for example, cultural activities such as the cooperative construction of artifacts (e.g. Caldwell and Millen 2008). Situating language in a broader context is in line with many developments in different branches of linguistics, including language evolution research. For instance, the multimodal nature of face-to-face communication has been strongly emphasized in recent research especially in cognitive linguistics, with an increasing interest in aspects like facial expression and in particular co-speech gesture (Müller 2013). Another research topic that is currently receiving more and more attention is the evolution of graphic codes and their impact on language and culture (e.g. Morin et al. 2018). Also, much research on cultural evolution in domains other than language draws explicit comparisons to the dynamics of language (e.g. Müller and Winters 2018), which shows that looking beyond language and taking other domains of culture into consideration can potentially also feed back into linguistic theory. Taking stock, then, it seems accurate to say that linguistics in general, as well as other humanities and cognitive sciences, has experienced an immense broadening of its potential scope. At the same time, there is much convergence between (sub-)disciplines that used to be fairly isolated. The complex adaptive systems approach suggests itself as a unified framework for studying the evolution of all kinds of cultural traits. However, one might argue that such a framework can only provide a rough scaffolding for theories of cultural evolution - after all, the strength of the complex adaptive systems approach is that it is so general, and that is also its weakness. An account of the evolution of a particular cultural trait like language needs a theory of how the complex adaptive system works, and why it changes, and potentially also how different complex adaptive systems interact. Kirby (2012) suggests that in the evolution of language, three dynamical systems interact that operate at different timescales: individual learning, sociocultural transmission, and biological evolution.

A theory of language evolution obviously needs to take all three timescales into account. Theories of language change will focus on sociocultural transmission, although they might benefit from not losing sight of the two other timescales. In the recent literature, usage-based construction grammar has repeatedly been suggested as a good candidate for modeling both the emergence of language from a hypothetical protolanguage and the development of fully-fledged language across the ontogenetic and historical timescales (e.g. Johansson 2016; Christiansen and Chater 2017; Pleyer 2017). This is quite remarkable given the fact that construction grammar originally emerged as a theory of linguistic knowledge on the level of the individual (see e.g. Hilpert 2014). Nevertheless, construction grammar enjoys growing popularity in the study of linguistic change (see e.g. Hilpert 2013; Traugott and Trousdale 2013; Barðdal et al. [eds.] 2015). The constructionist approach to language and its diachronic development bears many similarities to other usage-based approaches as well as to the study of grammaticalization. The notion of "construction" itself takes us all the way back to the Saussurean sign - a construction is just a form-meaning pair (see e.g. Goldberg 1995, Goldberg 2006). Importantly, construction grammar assumes that language can be described exhaustively in terms of constructions and 
that constructions are organized in a fine-grained taxonomic network, the so-called constructicon. A very similar conceptualization of linguistic knowledge can be found in Langacker's (1987) Cognitive Grammar (but here, the form-meaning pairs are called "symbolic units"). Also, the network metaphor has a long tradition in linguistics and in cognitive science in general (Diessel 2015), and it figures prominently in Hudson's (2010) Word Grammar, which in turn has influenced the use of the network metaphor in Traugott and Trousdale's (2013) constructionist approach to language change.

The network metaphor is inherently dynamic as it allows for strengthening and weakening of links between constructions. Also, new nodes or new links can emerge in the construction. ${ }^{9}$ The network metaphor also lends itself well to modelling associative patterns in other domains say, for instance, gesture - and can arguably also prove useful for characterizing non-linguistic communication systems (see e.g. Pleyer \& Hartmann 2016). In addition, the network metaphor has the advantage that it can be used on multiple levels: The idealization of "a language", "a dialect", or the like at the level of a population of speakers can be derived as an abstraction over networks of linguistic knowledge on the local level of the individual speaker.

But similar to the complex adaptive systems framework, the network metaphor and the concept of constructions can of course only provide the rough skeleton for a theory of language change. It has to be fleshed out with an account of how and why nodes and links are strengthened or weakened, appear or disappear. Pleyer and Winters (2014: 33), following Smith et al. (2013), argue that the factors governing linguistic strategies, which in turn can lead to reconfigurations of the constructicon, "can broadly be classified under the pressures for learnability and expressivity". The basic idea is fairly similar to accounts that have been proposed to explain grammaticalizion cycles (e.g. Haspelmath 1999b): The reuse of constructions - e.g. through the emergence of tightly integrated grammatical paradigms (Lehmann 2015: 141-146) - increases the learnability (or "compressibility", Smith et al. 2013) of a language. The pressure for expressivity, on the other hand, arises from language use in communication (Smith et al. 2013: 1048). New expressions can be coined to refer to novel concepts or to refer to existing concepts in a novel way (e.g. for pragmatic effect: "extravagance" in the sense of Keller 1994 and Haspelmath 1999b).

The idea of a trade-off between these two pressures bears striking similarities to von der Gabelentz' ([1892] 2016) idea that two opposing forces are at work in language history, which he calls Bequemlichkeitstrieb (roughly: 'drive towards ease') and Deutlichkeitstrieb ('drive towards clarity/expressivity'). Also, Haspelmath (1999b: 1050) points out that the concept of an interplay between "clarity" and "economy" has a long tradition in functionalist linguistics. As such, the pressures postulated in recent accounts of language evolution are not exactly new ideas. However, it is now possible to test these ideas in the laboratory and with the help of computational modelling (see e.g. Kirby et al. 2008; Smith et al. 2013).

\footnotetext{
${ }^{9}$ The ongoing debate on whether an "association-only" model should be preferred to a model with nodes and links (e.g. Schmid 2017) will not concern us here.
} 
This shows again the potential for cross-fertilization between historical linguistics and language evolution research. Especially on the side of historical linguistics, this potential seems to have remained largely unexplored so far. For example, it could be argued that iterated learning studies can give valuable clues to grammaticalization research. However, the findings from such experimental studies are largely ignored in the grammaticalization literature, and to my knowledge, no attempt has been made to design iterated learning experiments that explicitly test predictions of grammaticalization theory - perhaps partly because there is still some skepticism regarding the question whether iterated learning can reveal anything meaningful about natural language (Berwick and Chomsky 2017).

Taken together, then, the complex adaptive systems framework and usage-based approaches such as construction grammar offer a promising starting point for some kind of "Neo-Darwinian synthesis" between historical linguistics and language research as well as the wildly interdisciplinary array of fields that are currently starting to converge on a quest to collaboratively unravel the foundations of human cognition and culture in a holistic perspective. A number of questions remain open, however. For example, it is not always entirely clear which testable predictions the model makes. This is due to the generality of the model, which, however, is also a fully intentional "design feature" of most usage-based theorizing: Theoretical assumptions are kept at a bare minimum - they provide a "skeleton", as it were, that is to be fleshed out with the help of empirical findings. This is why Taylor (2012: 122) calls Cognitive Grammar, which is closely related to construction grammar, a "radically minimalist theory". A potentially more problematic aspect is that adopting a constructionist point of view entails multiple open questions such as: When can we actually speak of a construction? Are a raised eyebrow or a nonsmoking sign constructions in the broadest sense because they pair forms with (conventionalized) meanings, even though their form is non-linguistic? And when exactly does a fully compositional set of linguistic units become non-compositional enough that we can legitimately posit a construction (see e.g. Hilpert 2018: 26-28)? As much as the constructionist approach is compatible with the very broad, holistic perspective of the complex adaptive systems view, and despite its generality, it also entails a certain danger of digressing into discussions about very fine-grained details of theoretical modeling.

\section{Conclusion}

Jackendoff (2010) famously stated that "your theory of language evolution depends on your theory of language". One could add that the use of terms like "language evolution" and "language change" also partly depends on developments and research trends in the relevant fields. The starting point of this paper has been Haspelmath's $(2016,2020)$ observation that in some contexts, "language change" and "language evolution" have come to be used interchangeably. I have argued that this is not merely a matter of terminology but that it reflects a shift in perspective, which in turn can be situated in much broader developments that have massively 
changed the landscape of contemporary linguistics. Regarding historical linguistics and language evolution research, I have sketched multiple points of convergence especially between functionally-oriented branches of historical linguistics and research on the cultural evolution of language. At the same time, there is more and more convergence in both fields between those "camps" that focus more on the biological underpinnings of language and those that emphasize the cultural evolution and sociocultural situatedness of language. And across the board, many linguists have started to view language in its broader context.

This has implications for our understanding of language dynamics. Language is now seen as a complex adaptive system - but it is not the only one. As such, it can be illuminating to look beyond language and compare developmental patterns in language with the development of other complex adaptive systems in culture and biology. Language is seen as a cultural artifact - and arguably there are many parallels between the transmission of language and the transmission of other cultural traits, from concrete artifacts to immaterial cultural goods like traditions (see Morin 2015).

This view is not entirely new, of course. Note, for example, that Keller's (1994) invisible-hand theory is just as much about beaten paths and traffic jams (and economics, from where he borrowed the metaphor) as it is about language. But still, the increased interest in cultural evolution in domains other than language is a fairly new phenomenon. Similarly, the convergence between historical linguistics and language evolution research ultimately has its origins in the $19^{\text {th }}$ century. But it is only recently that both fields have started to converge again, after a fairly long period in which evolutionary approaches to language were rare and after the early years of language evolution research in which the relationship between the emerging field and the established discipline of historical linguistics was characterized by skepticism.

The current convergence offers some potential for an integrated theory of language evolution and change. As Christiansen and Chater (2017) put it, "common threads are emerging which create the basis for a radically different synthesis in the study of language." Like Johansson (2016) and Pleyer (2017), they see construction grammar as the most promising framework for understanding language and its evolution on the ontogenetic, historical, and potentially also on the biological timescale. Combining the network metaphor that lies at the heart of usage-based construction grammar with a complex adaptive systems framework provides a perfectly simple but powerful model that is inherently dynamic. This model is highly compatible and can easily be extended with elements from other theories, such as grammaticalization theory. However, it may also be too general in some respects.

Regarding the terminological distinction between language change and language evolution, I have argued that the latter encompasses the biological evolution of the cognitive prerequisites for language as well as the continued cultural evolution of languages. The term "language change" also refers to the cultural evolution of language but also encompasses lower-level changes that one would not normally describe as "language evolution." However, Christiansen and Chater (2017) argue that in the $20^{\text {th }}$ century, 
mainstream linguistic theory began to actively create distinctions (for example, competence versus performance, core versus periphery, learning a language versus processing that language; language change versus language evolution) that aimed to justify sealing off these different disciplinary perspectives on language from one another. (emphasis added)

From this point of view, the distinction between language change and evolution is eventually an artificial one. But it seems questionable to assume that the distinction was actively introduced. After all, scientific terminology is also a product of cultural evolution. So are models and theories of language change. As we have seen in Section 2, the trend towards holistic models of language evolution and change has emanated from a broad convergence that was driven by multiple factors. The holistic model offers a radical counter-perspective to the dominant models of language and language change in much of the $20^{\text {th }}$ century. Language is not seen as an absolutely special, innate module any more but as part of a complex array of cognitive and cultural capabilities. Likewise, language change is not conceptualized any more as parametersetting in language acquisition (Lightfoot 1991) or in terms of mechanistic laws, but as a constant reconfiguration of linguistic knowledge on the level of individuals and, consequently, on the level of populations.

While the developments that I have sketched in this paper might offer some important potential for convergence between different approaches and disciplines, there is also one important danger that should be mentioned: In the worst case, such integrative approaches like the complex adaptive systems view of language might lead to massive theoretical vagueness and as such to a largely a-theoretical, essentially descriptive view of language and language change that lacks explanatory power. But in the best case, it can help shed much theoretical ballast, allowing for an unprejudiced view on data from multiple sources, which in turn can contribute to the gradual evolution of an empirically informed theory of language emergence and change.

\section{Acknowledgments}

I would like to thank Michael Pleyer, Jonas Nölle, and Peeter Tinits for helpful discussions on the topic and/or comments on a previous draft on this paper. Remaining errors are of course my own.

\section{References}

Adelung, Johann Christoph. 1781. Über den Ursprung der Sprache und den Bau der Wörter, besonders der Deutschen. Ein Versuch. Leipzig: Breitkopf.

Adger, David. 2015a. Mythical myths: Comments on Vyvyan Evans' "The Language Myth." Lingua 158. 76-80.

Adger, David. 2015b. More misrepresentation: A response to Behme and Evans 2015. Lingua 162. 160-166.

Adli, Aria. 2004. Grammatische Variation und Sozialstruktur. Berlin: Akademie-Verlag. 
Arbib, Michael A. 2016. Primates, computation, and the path to language. Physics of Life Reviews 16. 105-122.

Atkinson, Quentin D. \& Russell D. Gray. 2005. Curious Parallels and Curious Connections: Phylogenetic Thinking in Biology and Historical Linguistics. Systematic Biology 54(4). 513-526.

Barceló-Coblijn, Lluís, Cory M. Cuthbertson, Kirsty E. Graham, Stefan Hartmann \& Michael Pleyer. 2016. Conference Report on Evolang 11. Journal of Language Evolution 1(2). $159-162$.

Barðdal, Jóhanna, Elena Smirnova, Lotte Sommerer \& Spike Gildea (eds.). 2015. Diachronic construction grammar. (Construction Approaches to Language 18). Amsterdam, Philadelphia: John Benjamins.

Beckner, Clay, Richard Blythe, Joan Bybee, Morten H. Christiansen, William Croft, Nick C. Ellis, John Holland, Jinyun Ke, Diane Larsen-Freeman \& Tom Schoenemann. 2009. Language is a Complex Adaptive System: Position Paper. Language Learning 59 Suppl. 1. $1-26$.

Behme, Christina \& Vyvyan Evans. 2015. Leaving the myth behind: A reply to Adger (2015). Lingua 162. 149-159.

Benítez-Burraco, Antonio \& Víctor M. Longa. 2010. Evo-Devo - of course, but which one? Some comments on Chomsky's analogies between the biolinguistic approach and evodevo. Biolinguistics 4(4). 308-323.

Bentz, Christian. 2018. Adaptive languages: an information-theoretic account of linguistic diversity. (Trends in Linguistics. Studies and Monographs 316). Berlin \& Boston: De Gruyter Mouton.

Berwick, Robert C. \& Noam Chomsky. 2017. Why only us: Recent questions and answers. Journal of Neurolinguistics 43. 166-177.

Bickerton, Derek. 1990. Language and species. Chicago: Chicago University Press.

Bouckaert, Remco, Philippe Lemey, Michael Dunn, Simon J. Greenhill, Alexander V. Alekseyenko, Alexei J. Drummond, Russell D. Gray, Marc A. Suchard \& Quentin D. Atkinson. 2012. Mapping the Origins and Expansion of the Indo-European Language Family. Science 337(6097). 957-960.

Boyd, Robert \& Peter J. Richerson. 1985. Culture and the evolutionary process. Chicago: Chicago University Press.

Boyd, Robert \& Peter J. Richerson. 1996. Why culture is common, but cultural evolution is rare. Proceedings of the British Academy 88.77-93.

Bowern, Claire \& Bethwyn Evans. 2015. Foundations of the new historical linguistics. In Claire Bowern \& Bethwyn Evans (eds.), The Routledge handbook of historical linguistics, 142. New York: Routledge.

Bybee, Joan. 2007. Diachronic Linguistics. In Dirk Geeraerts \& Hubert Cuyckens (eds.), The Oxford Handbook of Cognitive Linguistics, 945-987. Oxford: Oxford University Press.

Bybee, Joan L. 2010. Language, Usage and Cognition. Cambridge: Cambridge University Press.

Bybee, Joan. 2012. Domain-General Processes as the Basis for Grammar. In Maggie Tallerman \& Kathleen R. Gibson (eds.), The Oxford Handbook of Language Evolution, 528-536. Oxford: Oxford University Press.

Caldwell, Christine A. \& Ailsa E. Millen. 2008. Experimental models for testing hypotheses about cumulative cultural evolution. Evolution and Human Behavior 29(3). 165-171.

Campbell, Lyle. 1999. Historical Linguistics: An Introduction. Cambridge: MIT Press.

Campbell, Lyle. 2013. Historical Linguistics: An Introduction. 3rd edn. Cambridge: MIT Press.

Chomsky, Noam. 2010. Some simple evo devo theses: how true might they be for language? In Richard K. Larson, Viviane Deprez \& Hiroko Yamakido (eds.), The Evolution of Human Language, 45-62. Cambridge: Cambridge University Press. 
Christiansen, Morten H. \& Nick Chater. 2008. Language as Shaped by the Brain. Behavioral and Brain Sciences 31(5). 489-558.

Christiansen, Morten H. \& Nick Chater. 2017. Towards an integrated science of language. $\mathrm{Na}$ ture Human Behaviour 1(8). doi:10.1038/s41562-017-0163.

Collinge, N.E. 1995. History of historical linguistics. In E. F. K. Koerner \& R. E. Asher (eds.), Concise history of the language sciences: from the Sumerians to the cognitivists, 203212. New York: Pergamon.

Coppola, Marie \& Diane Brentari. 2014. From iconic handshapes to grammatical contrasts: longitudinal evidence from a child homesigner. Frontiers in Psychology 5. doi:10.3389/fpsyg.2014.00830.

Cornish, Hannah. 2010. Investigating how cultural transmission leads to the appearance of design without a designer in human communication systems. Interaction Studies 11(1). 112-137.

Creanza, Nicole, Merritt Ruhlen, Trevor J. Pemberton, Noah A. Rosenberg, Marcus W. Feldman \& Sohini Ramachandran. 2015. A comparison of worldwide phonemic and genetic variation in human populations. Proceedings of the National Academy of Sciences 112(5). $1265-1272$.

Croft, William. 2001. Radical Construction Grammar: Syntactic Theory in Typological Perspective. Oxford: Oxford University Press.

Crowley, Terry \& Claire Bowern. 2010. An introduction to historical linguistics. 4th edn. Oxford: Oxford University Press.

Dąbrowska, Ewa. 2015. What exactly is Universal Grammar, and has anyone seen it? Frontiers in Psychology 6. doi:10.3389/fpsyg.2015.00852.

Deacon, Terrence W. 1997. The Symbolic Species: The Co-Evolution of Language and the Brain. New York and London: Norton.

Dediu, Dan. 2015. An introduction to genetics for language scientists: current concepts, methods and findings. Cambridge, United Kingdom: Cambridge University Press.

Dediu, Dan \& Bart de Boer. 2016. Language evolution needs its own journal. Journal of Language Evolution 1(1). 1-6.

Diessel, Holger. 2015. Usage-Based Construction Grammar. In Ewa Dąbrowska \& Dagmar Divjak (eds.), Handbook of Cognitive Linguistics, 296-322. Berlin, New York: De Gruyter.

Evans, Vyvyan. 2014. The Language Myth: Why Language is Not an Instinct. Cambridge: Cambridge University Press.

Fischer, Olga. 2007. What counts as evidence in historical linguistics? In Martina Penke \& Anette Rosenbach (eds.), What counts as evidence in linguistics: the case of innateness, 249-281. Amsterdam, Philadelphia: John Benjamins.

Fitch, W. Tecumseh. 2010. The Evolution of Language. Cambridge: Cambridge University Press.

Fitch, W. Tecumseh. 2017. Empirical approaches to the study of language evolution. Psychonomic Bulletin \& Review 24(1). 3-33.

Foster, Mary LeCron. 2000. Finding the Themes: Family, Anthropology, Language Origins, Peace and Conflict. Interviews Conducted by Suzanne Riess in 2000. Berkeley: Regional Oral History Office, University of California, Berkeley. http://texts.cdlib.org/view?do-

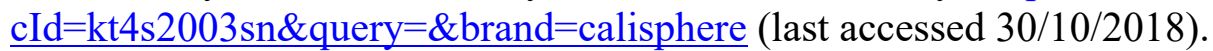

Frank, Roslyn M. 2008. The language-organism-species analogy: A complex adaptive systems approach to shifting perspective on 'language.' In Tom Ziemke, Jordan Zlatev \& Roslyn M. Frank (eds.), Body, Language and Mind: Vol. 2: Sociocultural situatedness, 215-262. (Cognitive Linguistics Research 35.2). Berlin \& New York: De Gruyter.

Frank, Roslyn M. \& Nathalie Gontier. 2010. On Constructing a Research Model for Historical Cognitive Linguistics (HCL): Some Theoretical Considerations. In Margaret E. Winters, 
Heli Tissari \& Kathryn Allan (eds.), Historical Cognitive Linguistics, 31-69. (Cognitive Linguistics Research 47). Berlin \& New York: De Gruyter.

von der Gabelentz, Georg. [1892] 2016. Die Sprachwissenschaft: Ihre Aufgaben, Methoden und bisherigen Ergebnisse. Berlin: Language Science Press.

Garrod, Simon, Nicolas Fay, John Lee, Jon Oberlander \& Tracy MacLeod. 2007. Foundations of Representation: Where Might Graphical Symbol Systems Come From? Cognitive Science 31(6). 961-987.

Goldberg, Adele E. 1995. Constructions: A Construction Grammar Approach to Argument Structure. Chicago, London: The University of Chicago Press.

Goldberg, Adele E. 2006. Constructions at Work: The Nature of Generalization in Language. Oxford: Oxford University Press.

Gray, Russell D., Quentin D. Atkinson \& Simon J. Greenhill. 2011. Language evolution and human history: what a difference a date makes. Philosophical Transactions of the Royal Society B: Biological Sciences 366(1567). 1090-1100.

Greenberg, Joseph H. 2005. Genetic Linguistics. Essays on Theory and Method. Oxford: Oxford University Press.

Goldin-Meadow, Susan, Carolyn Mylander \& Amy Franklin. 2007. How Children Make Language out of Gesture: Morphological Structure in Gesture Systems Developed by American and Chinese Deaf Children. Cognitive Psychology 55. 87-135.

Gong, Tao. 2011. Where could biolinguists and evolutionary linguists meet? Physics of Life Reviews 8(4). 373-374.

Gong, Tao, Yau Wai Lam, Xinying Chen \& Menghan Zhang. 2014. Evolutionary linguistics in the past two decades. Journal of Chinese Linguistics 42(2). 499-530.

Gray, Russell D. \& Quentin D. Atkinson. 2003. Language-tree divergence times support the Anatolian theory of Indo-European origin. Nature 426. 435-439.

Guzmán Naranjo, Matías. 2017. Unifying everything: Integrating quantitative effects into formal models of grammar. Proceedings of the 6th Conference on Quantitative Investigations in Theoretical Linguistics. Tübingen: University of Tübingen. https://publikationen.uni-tuebingen.de/xmlui/handle/10900/67216. (last accessed 31/10/2018)

Guzmán Naranjo, Matías. 2019. Analogical classification in formal grammar. Berlin: Language Science Press.

Harnard, Stevan R., Horst D. Steklis \& Jane Lancaster (eds.). 1974. Origin and evolution of language and speech. New York: New York Academy of Sciences.

Harris, Randy Allen. 1993. The Linguistics Wars. Oxford: Oxford University Press.

Haspelmath, Martin. 1999a. Optimality and diachronic adaptation. Zeitschrift für Sprachwissenschaft 18(2). 180-205.

Haspelmath, Martin. 1999b. Why is grammaticalization irreversible? Linguistics 37(6). 10431068.

Haspelmath, Martin. 2016. The evolution (or diachrony) of language evolution. https://dc.hypotheses.org/894 (last accessed 30/10/2018)

Haspelmath, Martin. 2020. Human linguisticality and the building blocks of languages. Frontiers in Psychology 10. doi 10.3389/fpsyg.2019.03056.

Hauser, Marc D., Noam Chomsky \& W. Tecumseh Fitch. 2002. The Faculty of Language: What Is It, Who Has It, and How Did It Evolve? Science 298. 1569-1579.

Heine, Bernd, Ulrike Claudi \& Friederike Hünnemeyer. 1991. Grammaticalization: A conceptual framework. Chicago: University of Chicago Press.

Heine, Bernd \& Tania Kuteva. 2002. World Lexicon of Grammaticalization. Cambridge: Cambridge University Press.

Heine, Bernd \& Tania Kuteva. 2007. The Genesis of Grammar: A Reconstruction. Oxford: Oxford University Press. 
Heine, Bernd \& Tania Kuteva. 2012. Grammaticalization Theory as a Tool for Reconstructing Language Evolution. In Maggie Tallerman \& Kathleen R. Gibson (eds.), The Oxford Handbook of Language Evolution, 511-527. Oxford: Oxford University Press.

Hewes, Gordon W. 1973. Primate communication and the gestural origin of language. Current Anthropology 14. 5-24.

Hilpert, Martin. 2013. Constructional Change in English: Developments in Allomorphy, Word Formation, and Syntax. Cambridge: Cambridge University Press.

Hilpert, Martin. 2014. Construction Grammar and its Application to English. Edinburgh: Edinburgh University Press.

Hilpert, Martin. 2018. Three open questions in diachronic construction grammar. In Evie Coussé, Peter Andersson \& Joel Olofsson (eds.), Grammaticalization meets construction grammar, 21-39. Amsterdam, Philadelphia: John Benjamins.

Hockett, Charles F. \& Robert Ascher. 1964. The human revolution. Current Anthropology 5(3). 135-147.

Hopper, Paul J. \& Elizabeth Closs Traugott. 2003. Grammaticalization. 2nd edn. Cambridge: Cambridge University Press.

Hruschka, Daniel J., Morten H. Christiansen, Richard A. Blythe, William Croft, Paul Heggarty, Salikoko S. Mufwene, Janet B. Pierrehumbert \& Shana Poplack. 2009. Building Social Cognitive Models of Language Change. Trends in Cognitive Sciences 13. 464-469.

Hudson, Richard. 2010. An Introduction to Word Grammar. Cambridge: Cambridge University Press.

Humboldt, Wilhelm von. 1836. Über die Verschiedenheit des menschlichen Sprachbaues und ihren Einfluß auf die geistige Entwickelung des Menschengeschlechts. Berlin: Akademie der Wissenschaften.

Jackendoff, Ray. 2002. Foundations of Language. Oxford: Oxford University Press.

Jackendoff, Ray. 2010. Your theory of language evolution depends on your theory of language. In Richard K. Larson, Viviane Déprez \& Hiroko Yamakido (eds.), The evolution of human language: Biolinguistic perspectives, 63-72. Cambridge: Cambridge University Press.

Johansson, Sverker. 2005. Origins of language: constraints on hypotheses. (Converging Evidence in Language and Communication Research 5). Amsterdam, Philadelphia: John Benjamins.

Johansson, Sverker. 2016. Protolanguage Possibilities in a Construction Grammar Framework. In Seán G. Roberts, Christine Cuskley, Luke McCrohon, Lluís Barceló-Coblijn, Olga Fehér \& Tessa Verhoef (eds.), The Evolution of Language. Proceedings of the 11th International Conference. http://evolang.org/neworleans/papers/149.html.

Joseph, Brian D. \& Richard Janda. 2003. On language, change, and language change - or, of history, linguistics, and historical linguistics. In Brian D. Joseph \& Richard Janda (eds.), The Handbook of Historical Linguistics, 1-180. Malden: Blackwell.

Keller, Rudi. 1994. Sprachwandel: Von der unsichtbaren Hand in der Sprache. Tübingen, Basel: Francke.

Kempson, Ruth \& Ronnie Cann. 2007. Diachronic syntax and dialogue modelling. Preliminaries for a dialogue-driven account of syntactic change. In Joseph C. Salmons \& Shannon Dubenion-Smith (eds.), Historical Linguistics 2005: Selected Papers from the 17th International Conference on Historical Linguistics, 73-101. (Current Issues in Linguistic Theory 284). Amsterdam and Philadelphia: John Benjamins.

Kirby, Simon. 2012. Language is an Adaptive System: The Role of Cultural Evolution in the Origins of Structure. In Maggie Tallerman \& Kathleen R. Gibson (eds.), The Oxford Handbook of Language Evolution, 589-604. Oxford: Oxford University Press.

Kirby, Simon. 2017. Culture and biology in the origins of linguistic structure. Psychonomic Bulletin \& Review 24(1). 118-137. 
Kirby, Simon, Hannah Cornish \& Kenny Smith. 2008. Cumulative Cultural Evolution in the Laboratory: An Experimental Approach to the Origins of Structure in Human Language. Proceedings of the National Academy of Sciences of the United States of America 105(31). 10681-10686.

Korostenskienė, Julija. 2017. Bridging the gap: Toward a cognitive semantic analysis of the Lithuanian superlexical prefix be-. In Stefan Hartmann (ed.), Yearbook of the German Cognitive Linguistics Association 2017, 195-210. Berlin, Boston: De Gruyter.

Kuhn, Thomas S. 1970. The Structure of Scientific Revolutions. 2nd edn. Chicago: The University of Chicago Press.

Labov, William. 1994. Principles of Linguistic Change. Vol. 1: Internal Factors. Malden: Blackwell.

Labov, William. 2001. Principles of Linguistic Change. Vol. 2: Social Factors. Malden: Blackwell.

Labov, William. 2010. Principles of Linguistic Change. Vol. 3: Cognitive and cultural factors. Malden: Blackwell.

Langacker, Ronald W. 1987. Foundations of Cognitive Grammar. Vol. 1: Theoretical Prerequisites. Stanford: Stanford University Press.

Lehmann, Christian. 2015. Thoughts on Grammaticalization. 3rd edn. (Classics in Linguistics 1). Berlin: Language Science Press.

Levinson, Stephen C. 2012. The Original Sin of Cognitive Science. Topics in Cognitive Science 4(3). 396-403.

Lightfoot, David. 1991. How to set parameters: arguments from language change. Cambridge, Mass: MIT Press.

Lupyan, Gary \& Rick Dale. 2010. Language Structure Is Partly Determined by Social Structure. PLoS ONE 5(1). e8559.

Maitz, Péter. 2012. Wohin steuert die Historische Sprachwissenschaft? Erkenntniswege und Profile einer scientific community im Wandel. In Péter Maitz (ed.), Historische Sprachwissenschaft, 1-27. (Studia Linguistica Germanica 110). Berlin, New York: De Gruyter.

Martins, Pedro Tiago, Maties Marí \& Cedric Boeckx. 2018. SRGAP2 and the gradual evolution of the modern human language faculty. Journal of Language Evolution 3(1). 67-78.

Massip-Bonet, Àngels. 2013. Language as a complex adaptive system: Towards an integrative linguistics. In Àngels Massip-Bonet \& Albert Bastardas-Boada (eds.), Complexity Perspectives on Language, Communication and Society, 35-60. Berlin, Heidelberg: Springer.

Meyer, Charles F. 2002. English corpus linguistics. An introduction. Cambridge: Cambridge University Press.

Morin, Olivier. 2015. How traditions live and die. Oxford: Oxford University Press.

Morin, Olivier, Piers Kelly \& James Winters. 2018. Writing, Graphic Codes, and Asynchronous Communication. Topics in Cognitive Science. doi:10.1111/tops.12386.

Mufwene, Salikoko S. 2001. The ecology of language evolution. (Cambridge Approaches to Language Contact). Cambridge: Cambridge University Press.

Müller, Cornelia. 2013. Introduction. In Cornelia Müller, Alan J. Cienki, Ellen Fricke, Silva H. Ladewig, David McNeill \& Sedinha Tessendorf (eds.), Body - language - communication: an international handbook on multimodality in human interaction, 1-6. (Handbooks of Linguistics and Communication Science 38.1). Berlin \& Boston: De Gruyter Mouton.

Müller, Stefan. 2013. Unifying everything: Some remarks on simpler syntax, construction grammar, minimalism, and HPSG. Language 89(4). 920-950.

Müller, Thomas F. \& James Winters. 2018. Compression in cultural evolution: Homogeneity and structure in the emergence and evolution of a large-scale online collaborative art project. (Ed.) Alex Mesoudi. PLOS ONE 13(9). e0202019. doi 10.1371/journal.pone.0202019. 
Murray, Robert W. 2006. Modern theories of linguistic change: An overview. In Sylvain Auroux, E.F.K. Koerner, Hans-Josef Niederehe \& Kees Versteegh (eds.), History of the Language Sciences. An international handbook on the evolution of the study of language from the beginnings to the present, Vol. 3, 2479-2500. Berlin, New York: De Gruyter.

Narrog, Heiko \& Bernd Heine (eds.). 2011. Oxford Handbook of Grammaticalization. Oxford: Oxford University Press.

Nölle, Jonas. 2014. A co-evolved continuum of language, culture and cognition: Prospects of interdisciplinary research. Studies about Languages 25. doi:10.5755/j01.sal.0.25.8504.

Osthoff, Hermann \& Karl Brugmann. 1878. Morphologische Untersuchungen auf dem Gebiete der indogermanischen Sprachen. Vol. 1. Leipzig: Hirzel.

Pereltsvaig, Asya \& Martin W. Lewis. 2015. The Indo-European Controversy. Facts and fallacies in historical linguistics. Cambridge: Cambridge University Press.

Pinker, Steven \& Paul Bloom. 1990. Natural language and natural selection. Behavioral and Brain Sciences 13. 707-784.

Pleyer, Michael. 2017. Protolanguage and mechanisms of meaning construal in interaction. Language Sciences 63. 69-90.

Pleyer, Michael \& Stefan Hartmann. 2016. Construction grammar for apes. In Seán G. Roberts, Christine Cuskley, Luke McCrohon, Lluís Barceló-Coblijn, Olga Fehér \& Tessa Verhoef (eds.), The Evolution of Language. Proceedings of the 11th International Conference.

Pleyer, Michael \& Stefan Hartmann. 2019. Constructing a consensus on language evolution? Convergences and differences between biolinguistic and usage-based approaches. Frontiers in Psychology: Language Sciences.

Pleyer, Michael \& James Winters. 2014. Integrating Cognitive Linguistics and Language Evolution Research. Theoria et Historia Scientiarum 11. 19-43.

Richerson, Peter J. \& Robert Boyd. 2005. Not by genes alone: how culture transformed human evolution. Chicago: University of Chicago Press.

Ritt, Nikolaus. 2004. Selfish Sounds and Linguistic Evolution: A Darwinian Approach to Language Change. Cambridge: Cambridge University Press.

Roberts, Séan \& James Winters. 2012. Social Structure and Language Structure: The New Nomothetic Approach. Psychology of Language and Communication 16(2). 89-112.

Rosenbach, Anette. 2008. Language change as cultural evolution: Evolutionary approaches to language change. In Regine Eckardt, Gerhard Jäger \& Tonjes Veenstra (eds.), Variation, selection, development: probing the evolutionary model of language change, 23-72. Berlin \& New York: Mouton de Gruyter.

Schleicher, August. 1863. Die Darwinische Theorie und die Sprachwissenschaft: Offenes Sendschreiben an Herrn Dr. Ernst Haeckel, o. Professor der Zoologie und Direktor des zoologischen Museums an der Universität Jena. 2nd ed. Weimar: Böhlau.

Schmid, Hans-Jörg. 2017. A framework for understanding entrenchment and its psychological foundations. In Hans-Jörg Schmid (ed.), Entrenchment and the Psychology of Language Learning. How We Reorganize and Adapt Linguistic Knowledge, 9-39. Berlin \& Boston: De Gruyter.

Schoenemann, P. Thomas. 2017. A Complex-Adaptive-Systems Approach to the Evolution of Language and the Brain. In Salikoko Mufwene, Christophe Coupe \& Francois Pellegrino (eds.), Complexity in Language, 67-100. Cambridge: Cambridge University Press.

Senghas, Ann. 2000. The Development of Early Spatial Morphology in Nicaraguan Sign Language. In S. Catherine Howell, Sarah A. Fish \& Thea Keith-Lucas (eds.), Proceedings of the 24th Annual Boston University Conference on Language Development, 696-707. Somerville, MA: Cascadilla Press.

Senghas, Ann. 2005. Language Emergence: Clues from a New Bedouin Sign Language. Current Biology 15(12). R463-R465. 
Smith, Kenny. 2018. How culture and biology interact to shape language and the language faculty. Topics in Cognitive Science. doi 10.1111/tops. 12377

Smith, Kenny, Monica Tamariz \& Simon Kirby. 2013. Linguistic Structure is an Evolutionary Trade-Off between Simplicity and Expressivity. In Markus Knauff, Michael Pauen, Natalie Sebanz \& Ipke Wachsmuth (eds.), Cooperative Minds: Social Interaction and Group Dynamics, 1348-1353. Austin, TX: Cognitive Science Society.

Steels, Luc. 2011. Modeling the Cultural Evolution of Language. Physics of Life Reviews 8. 339-356.

Tallerman, Maggie. 2012. Protolanguage. In Maggie Tallerman \& Kathleen R. Gibson (eds.), The Oxford Handbook of Language Evolution, 479-491. Oxford: Oxford University Press.

Tamariz, Mónica. 2014. Experiments and Simulations Can Inform Evolutionary Theories of the Cultural Evolution of Language. In Marco Pina \& Nathalie Gontier (eds.), The Evolution of Social Communication in Primates, vol. 1, 249-288. Cham: Springer. (16 October, 2017).

Tamariz, Monica. 2017. Experimental Studies on the Cultural Evolution of Language. Annual Review of Linguistics 3(1). 389-407.

Tamariz, Monica \& Simon Kirby. 2016. The cultural evolution of language. Current Opinion in Psychology 8. 37-43.

Taylor, John R. 1996. Possessives in English. Oxford: Oxford University Press.

Taylor, John R. 2012. The Mental Corpus: How Language is Represented in the Mind. Oxford: Oxford University Press.

Theofanopoulou, Constantina, Simone Gastaldon, Thomas O'Rourke, Bridget D. Samuels, Angela Messner, Pedro Tiago Martins, Francesco Delogu, Saleh Alamri \& Cedric Boeckx. 2017. Self-domestication in Homo sapiens: Insights from comparative genomics. (Ed.) Michael Klymkowsky. PLOS ONE 12(10). e0185306.

Trask, Larry. 2015. Historical linguistics. Revised and edited by Robert McColl Millar. 3rd edn. London: Routledge.

Traugott, Elizabeth Closs \& Graeme Trousdale. 2013. Constructionalization and Constructional Changes. (Oxford Studies in Diachronic and Historical Linguistics 6). Oxford: Oxford University Press.

Trotzke, Andreas. 2017. Sprachevolution: eine Einführung. Berlin, Boston: De Gruyter.

Van Trijp, Remi. 2014. Fitness landscapes in cultural language evolution: A case study on German definite articles. In Erica A. Cartmill, Séan Roberts, Heidi Lyn \& Hannah Cornish (eds.), The Evolution of Language: Proceedings of the 10th International Conference, 334-341. Singapore: World Scientific.

Walkden, George. 2013. Null subjects in Old English. Language Variation and Change 25(02). $155-178$.

Zimmermann, Richard. 2017. Formal and quantitative approaches to the study of syntactic change. Three case studies from the history of English. $\mathrm{PhD}$ thesis: University of Geneva. 